\title{
Grapevine acclimation to water deficit: the adjustment of stomatal and hydraulic conductance differs from petiole embolism vulnerability
}

\author{
Uri Hochberg ${ }^{1,2}$ - Andrea Giulia Bonel ${ }^{1}$ Rakefet David-Schwartz ${ }^{3}$. \\ Asfaw Degu ${ }^{4} \cdot$ Aaron Fait $^{4} \cdot$ Hervé Cochard $^{2} \cdot$ Enrico Peterlunger $^{1}$. \\ Jose Carlos Herrera ${ }^{1,5}$
}

Received: 11 January 2017/Accepted: 6 February 2017/Published online: 18 February 2017

(c) The Author(s) 2017. This article is published with open access at Springerlink.com

\begin{abstract}
Main conclusion Drought-acclimated vines maintained higher gas exchange compared to irrigated controls under water deficit; this effect is associated with modified leaf turgor but not with improved petiole vulnerability to cavitation.

A key feature for the prosperity of plants under changing environments is the plasticity of their hydraulic system. In the present research we studied the hydraulic regulation in grapevines (Vitis vinifera $\mathrm{L}$.) that were first acclimated for 39 days to well-watered (WW), sustained water deficit (SD), or transient-cycles of dehydration-rehydrationwater deficit (TD) conditions, and then subjected to varying degrees of drought. Vine development under SD led to the smallest leaves and petioles, but the TD vines had the
\end{abstract}

Electronic supplementary material The online version of this article (doi:10.1007/s00425-017-2662-3) contains supplementary material, which is available to authorized users.

Jose Carlos Herrera

jose.herrera@boku.ac.at

1 Department of Agricultural, Food, Environmental and Animal Sciences, University of Udine, Via delle Scienze 206, 33100 Udine, Italy

2 PIAF, INRA, Univ. Clermont-Auvergne, 63100 Clermont-Ferrand, France

3 Institute of Plant Sciences, Agricultural Research Organization, The Volcani Centre, 50250 Bet Dagan, Israel

4 The French Associates Institute for Agriculture and Biotechnology of Drylands, Ben Gurion University of the Negev, Sede Boqer, Israel

5 Division of Viticulture and Pomology, Department of Crop Sciences, University of Natural Resources and Life Sciences Vienna (BOKU), Konrad Lorenz Str. 24, 3430 Tulln, Austria smallest mean xylem vessel and calculated specific conductivity $\left(k_{\mathrm{ts}}\right)$. Unexpectedly, both the water deficit acclimation treatments resulted in vines more vulnerable to cavitation in comparison to WW, possibly as a result of developmental differences or cavitation fatigue. When exposed to drought, the SD vines maintained the highest stomatal $\left(g_{\mathrm{s}}\right)$ and leaf conductance $\left(k_{\text {leaf }}\right)$ under low stem water potential $\left(\Psi_{\mathrm{s}}\right)$, despite their high xylem vulnerability and in agreement with their lower turgor loss point ( $\left.\Psi_{\mathrm{TLP}}\right)$. These findings suggest that the down-regulation of $k_{\text {leaf }}$ and $g_{\mathrm{s}}$ is not associated with embolism, and the ability of drought-acclimated vines to maintain hydraulic conductance and gas exchange under stressed conditions is more likely associated with the leaf turgor and membrane permeability.

Keywords Drought acclimation - Osmotic adjustment . Turgor $\cdot$ Vulnerability to cavitation $\cdot$ Water stress $\cdot$ Xylem architecture

$\begin{array}{ll}\text { Abbreviations } \\ \text { DOE } & \text { Day after the initiation of the irrigation experiment } \\ g_{\mathrm{s}} & \text { Stomatal conductance } \\ k_{\text {leaf }} & \text { Leaf hydraulic conductance specific to leaf area } \\ k_{\text {plant }} & \text { Whole plant hydraulic conductance specific to leaf } \\ & \text { area } \\ k_{\mathrm{t}} & \text { Petiole theoretical hydraulic conductivity } \\ k_{\mathrm{ts}} & \text { Petiole theoretical specific hydraulic conductivity } \\ \text { PLC } & \text { Percentage loss of conductivity } \\ \text { SD } & \text { Sustained water deficit } \\ \text { TD } & \text { Transient water deficit } \\ \text { VC } & \text { Xylem vulnerability curve } \\ \text { WW } & \text { Well-watered } \\ \theta & \text { Soil water content } \\ \Psi & \text { Water potential (1, leaf; s, stem) } \\ \Psi_{\text {TLP }} & \text { Turgor loss point }\end{array}$




\section{Introduction}

The morphology, anatomy, and physiology of the entire hydraulic path of the plant, from the root hairs up to the stomata, will define the plant's capacity to uptake, transport and transpire water (Sperry et al. 2002). A change in water availability or demand will be followed by a quick (minutes) regulation of the transpiration. If the new environmental condition is maintained for a longer period (days), the plant will slowly modify its hydraulic system to improve its compatibility with the changing environment (i.e. hydraulic acclimation; Lovisolo et al. 2010).

The fastest regulation of transpiration occurs at the leaf level, where the gradient of water potentials is the largest (Van den Honert 1948). The importance of stomatal regulation of transpiration has been acknowledged for over a century (Darwin 1898), but evidence from the last decade suggests that leaf hydraulic conductance $\left(k_{\text {leaf }}\right)$ is also an important regulator of transpiration, possibly through amplification of the hydraulic signal (Sack and Holbrook 2006; Brodribb et al. 2007; Scoffoni et al. 2014). In response to declining soil water content $(\theta)$ and stem water potential $\left(\Psi_{\mathrm{s}}\right)$, both stomatal conductance $\left(g_{\mathrm{s}}\right)$ and $k_{\text {leaf }}$ are quickly downregulated, resulting in immediate decline of transpiration.

Conversely, plant acclimation to water deficit involves slower processes, including the modification of fundamental hydraulic characteristics. To begin with, the most noticeable effect is the modification of leaf area (i.e. the evaporative surface), either through growth seizure, or even by the shedding of leaves. Additionally, evidence for a broad hydraulic adjustment showed that during drought acclimation the size of xylem vessels and their conductive capacity is normally smaller (Lovisolo and Schubert 1998), xylem resistance to cavitation is improved (Awad et al. 2010; Fichot et al. 2010), and osmolites accumulation is increased leading to lower turgor loss point ( $\Psi_{\mathrm{TLP}}$; Patakas et al. 1997). These acclimations to drought mirror the characteristics that are common to species adapted to arid environments (Kolb and Sperry 1999; Brodribb et al. 2003; Bartlett et al. 2014), and enable the plant to sustain its new surroundings.

Assuming that such hydraulic adjustments occur during acclimation to water deficit, the mechanical interaction between $\theta, \Psi_{\mathrm{s}}$, turgor pressure, $k_{\text {leaf }}$, and $g_{\mathrm{s}}$ should be modified following the acclimation. Namely, the fast control of transpiration should be modified in respect to the slow changes the hydraulic system underwent during the acclimation period. For example, acclimation leading to smaller vessels should subsequently result in higher resistance of the xylary pathway, leading to either a larger gradient between the soil and leaf water potential $\left(\Psi_{1}\right)$, or reduction of the transpiration rates. Similarly, acclimation leading to lower $\Psi_{\mathrm{TLP}}$ should allow vines to maintain higher $g_{\text {s }}$ under similar $\Psi_{\mathrm{s}}$ (Scarth 1927). These modifications are expected to be finely tuned to assure that the adjustment of stomatal regulation leads to tensions that the xylem could sustain without danger of embolism propagation. Nonetheless, data on the interaction between the fast stomatal regulation and the slow hydraulic modification during acclimation to drought is lacking. The present experiment was designed to evaluate the effect of acclimation on drought stress responses by first subjecting grapevines to a drought acclimation period and then exposing the drought-acclimated vines to a successive water deficit. We hypothesized that the adjustments developed during the acclimation (e.g. modified xylem architecture, xylem vulnerability to cavitation, and $\Psi_{\text {TLP }}$ ) will cause changes in $k_{\text {leaf }}$ and $g_{\mathrm{s}}$ regulation in a manner that both allows gas exchange and retains the hydraulic integrity of the xylem under future low $\Psi$ conditions.

\section{Materials and methods}

This study consisted of two main experiments: (1) a 39-day acclimation period to drought, and (2) a dehydration experiment on the drought-acclimated vines (schematized in Fig. 1). During the 39-day acclimation period, grapevines were subjected to three different irrigation treatments: sustained water deficit (SD), transient water deficit-three cycles of dehydration-rehydration-(TD), and well-watered (WW). Treatments during the acclimation period were designed to simulate what might happen in open fields, where growing plants could experience abundant water availability, little water availability, or cycles of stress and recovery (for instance when irrigation is performed once a week). The soil volumetric water content $(\theta)$, leaf abscisic acid concentration (ABA), and stomatal conductance $\left(g_{\mathrm{s}}\right)$ were used to characterize the degree of water stress for each of the acclimation treatments. Following the 39-day acclimation period, all plants were rehydrated and maintained under well-watered conditions for a month in order to avoid long-term influence of chemical signaling (i.e. $\mathrm{ABA}$ ). $\mathrm{ABA}$ is accumulated in leaves during drought and is responsible for maintaining stomata closed even after re-watering until it is completely metabolized (Tombesi et al. 2015). During this period, the adjustment of leaf physiology was evaluated for each treatment through various measurements: leaf pressure volume curves, petiole vulnerability curves, and crosssection anatomy. Finally, in order to observe the leaves' hydraulic regulation resulting from acclimation, plants were subjected to a second water deficit experiment. Leaf water potential $\left(\Psi_{1}\right)$, stem water potential $\left(\Psi_{\mathrm{s}}\right)$, and stomatal conductance $\left(g_{\mathrm{s}}\right)$ were measured on three different 


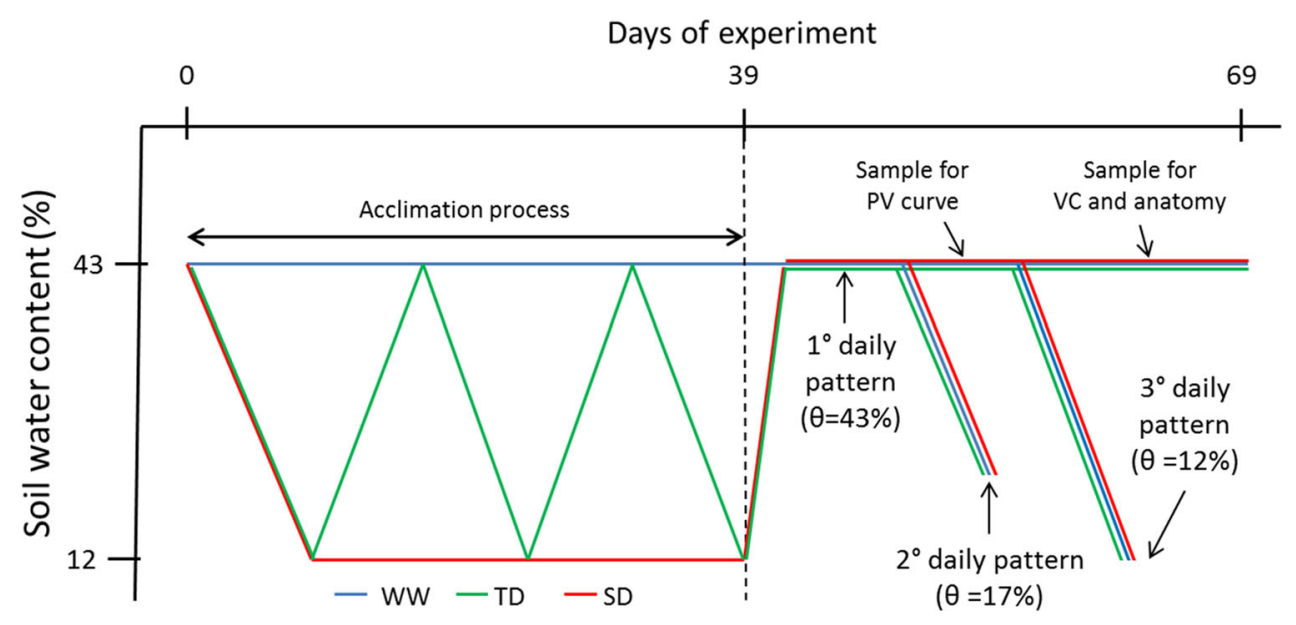

Fig. 1 Description of the experimental timeline for the well-watered (WW), transient deficit (TD), and sustained deficit (SD) treatments. Following the 39-day acclimation period, the daily pattern of stomatal conductance and water potential under three different volumetric soil

days. For each of these 3 days, the soil was maintained at different $\theta$, reflecting different degrees of water stress.

\section{Growth conditions and irrigation treatments}

The experiment took place in the greenhouse complex at the University of Udine (northeastern Italy). The experiment was conducted on 150 cuttings of Vitis vinifera cv. Merlot (clone R3) grafted on $\mathrm{SO}_{4}(V$. berlandieri $\times V$. riparia cv. ISV-VCR4) rootstock (Vivai Cooperativi Rauscedo VCR, Rauscedo, Italy) and planted in January 2015 in $7 \mathrm{~L}$ pots filled with exactly $1.2 \mathrm{~kg}$ (dry weight) of commercial potting media (Gebr. Brill Substrate Type 1, Georgsdorf, Germany). Budbreak occurred on 1 March 2015 and only one shoot per plant was left to develop vertically. The temperature and humidity were continuously monitored (Vaisala HMP45C, Helsinki, Finland) with average daily temperature ranging from 12.8 to $26.1{ }^{\circ} \mathrm{C}$ (Fig. S1).

The vines were irrigated for a period of 39 days according to the three different treatments. Each treatment had 50 vines. Pots were arranged in a completely randomized design. Irrigation treatments started when the vines had three mature leaves, 1 month after budbreak, and until then all pots were irrigated as the well-watered treatment. The WW treatment was drip-irrigated three times a day, with a gradual increase of irrigation volumes $\left(0.5-1.5 \mathrm{~L} \mathrm{day}^{-1}\right.$ according to plant growth and water demand) to maintain $\theta$ near field capacity. This high frequency of irrigation ensured that the pot water capacity was not a limiting factor. In the SD treatment, irrigation was withheld to deplete the soil water content until vines reached mid-morning $g_{\mathrm{s}}$ values of $0.05-0.15 \mathrm{~mol} \mathrm{H}_{2} \mathrm{O} \mathrm{m}^{-2} \mathrm{~s}^{-1}$. These mid-morning $g_{\mathrm{s}}$ values both reflect moderate stress conditions and allows the vines water contents $(\theta)$ were evaluated on three different days. Additionally, pressure volume curve (PV), the petiole xylem vulnerability curve ( $\mathrm{VC}$ ), and the petiole anatomy were evaluated in the plants acclimated to different treatments

to maintain growth (Flexas et al. 2002). Once the desired $g_{\mathrm{s}}$ was reached-on the 12th day after the initiation of the irrigation experiment (DOE) - pots were manually irrigated on a daily basis using a measuring beaker to maintain a constant pot weight (scale max $120 \mathrm{~kg}$, reading unit: $10 \mathrm{~g}$ ) that should lead to a similar rate of $g_{s}$. Irrigation values were between $50-100 \mathrm{~mL}$ day $^{-1}$ for the SD treatment. The transient water deficit treatment (TD) underwent three dehydration-rehydration cycles. In each cycle, irrigation was withheld to deplete $\theta$ until $g_{\mathrm{s}}$ levels of $0.05-0.15 \mathrm{~mol} \mathrm{H}_{2-}$ $\mathrm{O} \mathrm{m}^{-2} \mathrm{~s}^{-1}$ were measured (i.e. as in $\mathrm{SD}$ ), and irrigated immediately after, similar to the WW treatment for 6 days. Following the 39 days of different treatments, all plants were irrigated as the WW treatment until their physiological adjustments were evaluated as described below.

To assess the response of the vines to drought following the acclimation period, the vines' daily course of $g_{\mathrm{s}}$ and $\Psi_{\mathrm{s}}$ were measured on three different days. On each of these days, the pots were dried to different $\theta$ (i.e. 43,17 , and $12 \%$ ), which corresponded to no stress, moderate stress, and severe stress conditions, respectively. Specifically, daily patterns were measured 6 (no stress), 16 (moderate stress), and 19 (severe stress) days after the end of the acclimation period (Fig. 1). Different vines were measured on each day and at each time point (three plants per treatment at each time point). Therefore, the measured vines were not exposed to stress between the end of the acclimation period and the day on which they were measured. Moreover, because the vines from different treatments had different leaf areas (resulting in different transpiration rates) that might lead to differences in $\theta$ of their respective pots, each pot was manually irrigated every $2 \mathrm{~h}$ to maintain a constant weight and assure that similar $\theta$ 's were experienced by all the vines during the whole day of measurements. 


\section{Leaf area and vine mass}

To assess the vine growth during the acclimation period, total plant leaf area was measured on the 1 st and 41 st DOE. The leaf area of three vines per treatment was destructively measured at each time point, using a leaf area meter (LiCor LI-3100). Additionally, the above-ground current year growth of the same vines was weighed to determine the fresh weight and dry weight (after 5 days at $70{ }^{\circ} \mathrm{C}$ ).

\section{Gas exchange, water potential $(\Psi)$ and hydraulic conductance $(k)$}

Measurements of gas exchange and water potential $(\Psi$, $\mathrm{MPa}$ ) were performed on fully expanded leaves. To measure the water potential, the leaves were bagged immediately before (for leaf water potential, $\Psi_{1}$ ) or $1 \mathrm{~h}$ before (for stem water potential, $\Psi_{\mathrm{s}}$ ) they were excised from the shoot using a sharp blade. While still bagged, the leaves were placed into the pressure chamber (Soil Moisture Co., Santa Barbara, CA, USA) with the petiole protruding from the chamber lid. The chamber was pressurized using a nitrogen tank, and $\Psi$ was recorded when the initial xylem sap was observed emerging from the cut end of the petiole. Predawn water potential $\left(\Psi_{\mathrm{PD}}\right)$ was measured as $\Psi_{\mathrm{s}} 30 \mathrm{~min}$ before first light.

The LI-6400 portable photosynthesis system (Li-Cor Inc, NE, US) device was used to measure $g_{\mathrm{s}}\left(\mathrm{mol} \mathrm{H}_{2} \mathrm{O}\right.$ $\left.\mathrm{m}^{-2} \mathrm{~s}^{-1}\right)$ and $E\left(\mathrm{mmol} \mathrm{H}_{2} \mathrm{O} \mathrm{m}^{-2} \mathrm{~s}^{-1}\right)$ using ambient humidity and temperature.

The leaf hydraulic conductance ( $k_{\text {leaf }}$ specific to leaf area; Eq. 1$)$ and whole plant hydraulic conductance $\left(k_{\text {plant }}\right.$ specific to leaf area; Eq. 2) were calculated based on the Ohm's law analogy as following:

$k_{\text {leaf }}=\frac{E}{\Psi_{\mathrm{s}}-\Psi_{1}}$,

$k_{\text {plant }}=\frac{E}{\Psi_{\mathrm{PD}}-\Psi_{1}}$.

\section{Xylem vulnerability curves and pressure volume curves}

To assess the physiological adjustments the vines underwent during the acclimation period, pressure volume curves (PV) and xylem vulnerability curves (VC) were performed 10-15 days (for PV) or 20-30 days (for VC) after the end of the acclimation period on petioles or leaves, respectively, that were differentiated during the acclimation period (i.e. after imposing different irrigation treatments). Different growth rates could alter the relationship between leaf age and development (Rapaport et al. 2014). Hence, since much faster growth was noted in the WW treatment (Table 1), it probably had a larger proportion of younger leaves (in days) and possibly a lower proportion of developed leaves. The potential effect of such differences, which are common in most long-term stress experiments, was controlled by selecting leaves of similar age. To know the differentiation time of the leaves, the highest internode bearing a $3 \mathrm{~cm}$ length leaf was marked on the 12th day of the experiment, when both the SD and TD treatment reached the desired low $g_{\mathrm{s}}$ values. The three leaves above the mark were used for these analyses.

Xylem vulnerability curves were acquired exactly as described in the protocol presented by Hochberg et al. (2016b). Briefly, the vines were cut at their rootstock and dehydrated to a range of stem water potentials. Following dehydration the vines were covered with large black plastic bags for at least 20 min to allow water pressure stabilization. Two leaves per shoot were measured and averaged to determine $\Psi_{\mathrm{s}}$ and the shoot was submerged under $4 \mathrm{~cm}$ of water for $20 \mathrm{~min}$ to relax the tension. Hochberg et al. (2016b) showed that short xylem relaxation does not lead to refilling and allows an accurate evaluation of embolism. Following xylem relaxation, three petioles ( $4 \mathrm{~cm}$ long) per shoot were cut under water and connected to the Xyle'm hydraulic apparatus (Bronkhorst, Montigny-lès-Cormeilles, France). Distilled and degassed water, supplemented with

Table 1 Total leaf area per vine (LA), plant dry weight, single leaf area (LA), and number of leaves per vine (\#leaves) of the well-watered (WW), transient water deficit (TD), and sustained water deficit (SD) acclimation treatments on the 1st and 41st day of experiment (DOE)

\begin{tabular}{|c|c|c|c|c|c|}
\hline DOE & Treatment & Total LA $\left(\mathrm{cm}^{2}\right.$ vine $\left.^{-1}\right)$ & Dry weight $^{*}\left(\mathrm{~g}\right.$ vine $\left.^{-1}\right)$ & Single LA $\left(\mathrm{cm}^{2}\right.$ leaf $\left.{ }^{-1}\right)$ & No. of leaves per vine \\
\hline \multirow[t]{3}{*}{1} & WW & $268.4 \pm 37.2^{\mathrm{a}}$ & $1.2 \pm 0.2^{\mathrm{a}}$ & $57.2 \pm 2.2^{\mathrm{a}}$ & $7.3 \pm 1.45^{\mathrm{a}}$ \\
\hline & TD & $327.0 \pm 17.3^{\mathrm{a}}$ & $1.4 \pm 0.1^{\mathrm{a}}$ & $64.6 \pm 3.4^{\mathrm{a}}$ & $7.0 \pm 0.10^{\mathrm{a}}$ \\
\hline & WD & $277.4 \pm 23.7^{\mathrm{a}}$ & $1.4 \pm 0.02^{\mathrm{a}}$ & $56.1 \pm 3.8^{\mathrm{a}}$ & $6.7 \pm 0.33^{\mathrm{a}}$ \\
\hline \multirow[t]{3}{*}{41} & WW & $3147.3 \pm 394.2^{\mathrm{a}}$ & $27.9 \pm 2.3^{\mathrm{a}}$ & $119.0 \pm 5.8^{\mathrm{a}}$ & $16.7 \pm 1.45^{\mathrm{a}}$ \\
\hline & $\mathrm{TD}$ & $2570.0 \pm 205.5^{\mathrm{b}}$ & $19.4 \pm 1.8^{\mathrm{b}}$ & $109.2 \pm 1.1^{\mathrm{b}}$ & $15.0 \pm 1.15^{\mathrm{b}}$ \\
\hline & WD & $1205.6 \pm 49.9^{\mathrm{c}}$ & $8.5 \pm 0.9^{c}$ & $94.9 \pm 3.3^{\mathrm{c}}$ & $9.3 \pm 0.67^{\mathrm{c}}$ \\
\hline
\end{tabular}

Values are mean $\pm \mathrm{SE}(n=3)$. Different letters within a column and for each DOE indicate significant differences between treatments $(P<0.05)$ by Tukey Honest Significant Difference (HSD) test

* Only the current year growth was measured. 
$10 \mathrm{mM} \mathrm{KCl}$, was used as perfusion liquid for all measurements. The initial hydraulic conductance $\left(k_{\mathrm{i}}\right)$ was determined with a hydrostatic pressure gradient of 4$5 \mathrm{kPa}$. To measure the maximum conductance $\left(k_{\max }\right)$, the petioles were flushed for a period of 2 min with water pressurized at $0.18 \mathrm{MPa}$. PLC was calculated as:

$\mathrm{PLC}=100 \times\left(1-\frac{k_{i}}{k_{\max }}\right)$.

The pressure volume (PV) curves were acquired as described in Turner (1988). Leaf weight and, immediately after, leaf water potential $\left(\Psi_{1}, \mathrm{MPa}\right)$, were periodically measured during leaf dehydration. The turgor loss point $\left(\Psi_{\mathrm{TLP}}\right)$, osmotic potential at $100 \%$ turgor $\left(\pi_{100}\right)$, and cell modulus of elasticity $(\varepsilon)$ were estimated through the analysis of the PV curve (Turner 1988).

\section{Xylem architecture and theoretical specific hydraulic conductivity}

The xylem architecture of seven of the petioles used for the xylem vulnerability curve analysis was examined. Samples were incubated in $70 \%$ ethanol and stored at $4{ }^{\circ} \mathrm{C}$ until dehydration. Fixed tissue was dehydrated at room temperature in a graded series of ethanol $(1 \mathrm{~h}$ each at 70, 90, 95 and $100 \%)$. After dehydration, the samples were placed in small plastic net boxes and incubated in isopropyl alcohol inside a microwave histoprocessor (Milestone Histo5, Kalamazoo, MI, USA) for $105 \mathrm{~min}$ at $70{ }^{\circ} \mathrm{C}$. To ensure adequate removal of isopropyl alcohol, a vacuum drying step was introduced, where the pressure was 660 mbar. Wax impregnation was performed under vacuum condition $\left(10 \min 70{ }^{\circ} \mathrm{C} 500 \mathrm{mbar}, 10 \mathrm{~min} 70{ }^{\circ} \mathrm{C} 400 \mathrm{mbar}, 4 \mathrm{~min}\right.$ $70{ }^{\circ} \mathrm{C} 300 \mathrm{mbar}, 4 \mathrm{~min} 70^{\circ} \mathrm{C} 200 \mathrm{mbar}, 3 \min 70^{\circ} \mathrm{C}$ $150 \mathrm{mbar}, 89 \mathrm{~min} 65^{\circ} \mathrm{C} 100 \mathrm{mbar}$ ). Cross-sections of $15 \mu \mathrm{m}$ in thickness were prepared using a rotary microtome (Leica, RM2245), floated in water at $42{ }^{\circ} \mathrm{C}$ to stretch ribbons and incubated on microscope slides at $42{ }^{\circ} \mathrm{C}$ overnight. The sections were then stained with Safranin-O and Fast-green. The sectioned material was observed using a Leica IM1000 microscope, and digital images were taken using a CCD camera DC2000 (Leica, Wetzlar, Germany).

Since petioles are nearly symmetrical, half of the vessels (later extrapolated to the whole petiole) were manually (i.e. without an automated algorithm) labeled, and their areas were measured using the appropriate function of the ImageJ software (Abràmoff et al. 2004). Based on the radius of each vessel, theoretical hydraulic conductivity $\left(k_{\mathrm{t}}\right.$; mmol m s${ }^{-1} \mathrm{MPa}^{-1}$ ) was calculated with the modified Hagen-Poisseuille's law described by Tyree and Ewers (1991): $k_{\mathrm{t}}=\frac{\pi \rho}{128 \eta} \sum_{i=1}^{n}\left(d_{i}^{4}\right)$,

where $d$ is the diameter of the vessel in meters, $\rho$ is the fluid density (assumed to be $1000 \mathrm{~kg} \mathrm{~m}^{-3}$ ) and $\eta$ is the viscosity (assumed to be $1 \times 10^{-9} \mathrm{MPa}$ s). The theoretical specific hydraulic conductivity $\left(k_{\mathrm{ts}}\right)$ was calculated by normalizing $k_{\mathrm{t}}$ to the leaf area $(\mathrm{LA}): k_{\mathrm{ts}}=k_{\mathrm{t}} / \mathrm{LA}$. The relative proportion of the number of vessels belonging to different size categories and their contribution to $k_{\mathrm{t}}$ was evaluated.

\section{Abscisic acid}

Abscisic acid (ABA), a known marker for water stress, was monitored in all treatment during the acclimation period to assure that the 6 days of hydration allowed the TD to eliminate signs of stress. One leaf per plant for four plants per treatment $(n=4)$ was detached and immediately frozen under liquid nitrogen on the 13th, 18th, 29th, 34th, and 39th DOE, corresponding to the maximum and minimum peaks of the dehydration-rehydration cycles of TD. The leaves were maintained under $-80^{\circ} \mathrm{C}$ for 60 days before they were extracted and analyzed using UPLC-QTOF-MS system (Waters Q-TOF XevoTM, Waters MS Technologies) exactly as described in Hochberg et al. (2013). ABA concentration was determined using a standard calibration curve of $\pm \mathrm{ABA}$ (OlChemIm, Olomouc, Czech Republic).

\section{Statistical analysis}

In order to evaluate the $\Psi_{\mathrm{s}}$ in which 50\% PLC is measured $\left(\mathrm{PLC}_{50}\right)$, vulnerability curve data were fit to an exponential sigmoidal regression as follows:

$\mathrm{PLC}=\frac{100}{1+e^{\alpha\left(\Psi_{\mathrm{s}}-\mathrm{PLC}_{50}\right)}}$.

To test for significant differences between treatments, coefficients $\alpha$ and PLC $_{50}$ were determined from the linearized form of Eq. 5, as follows:

$\ln (100 /$ PLC -1$)=\alpha \times\left(\Psi_{\mathrm{s}}-\mathrm{PLC}_{50}\right)$.

Transformed values were analyzed through a regression model with $\Psi_{\mathrm{s}}$, the treatment, and their interaction as model effects.

Other parameters of the different treatment were averaged and compared using a Tukey HSD test $(P<0.05$; JMP 7.0, SAS Institute, Cary, NC, USA). Differences and relationships were considered significant at $P<0.05$. Figures were created using Sigmaplot 12.5 (Systat Software Inc.). 


\section{Results}

\section{Acclimation period}

Irrigation strategies successfully maintained the volumetric soil water content $(\theta)$ significantly different between treatments (Fig. 2a; Table S1). The $\theta$ of the well-watered (WW) treatment was maintained above $36 \%$ during the entire experiment, while that of the sustained deficit (SD)

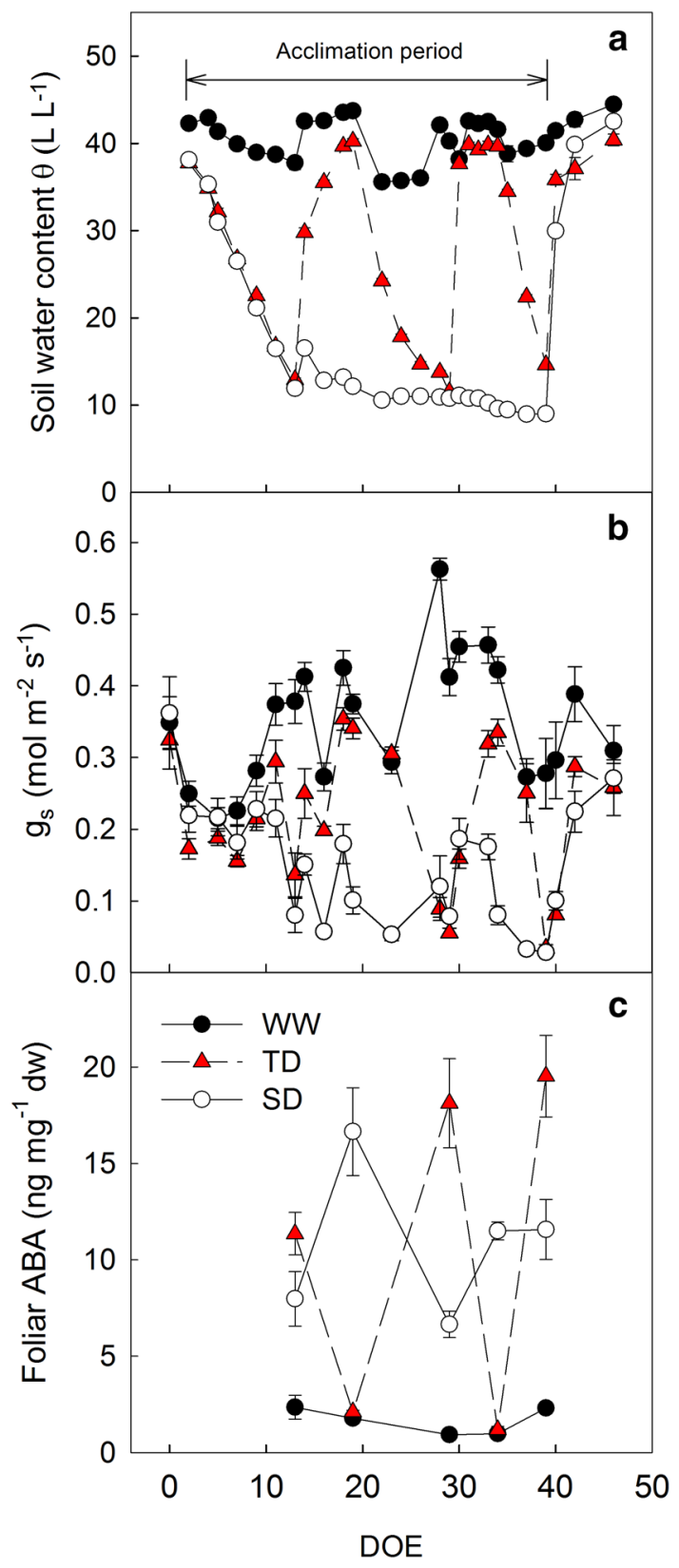

Fig. 2 Soil water content $(\mathbf{a}, \theta)$, stomatal conductance $\left(\mathbf{b}, g_{\mathrm{s}}\right)$, and foliar abscisic acid (ABA) concentration (c) in the well-watered (WW), transient deficit (TD), and sustained deficit (SD) treatments during the acclimation period. Differential irrigation commenced on day 0 of experiment (DOE). Data are mean $\pm \mathrm{SE}, n=6$ treatment was lower than $13 \%$ starting on the 14 th and until the 39th DOE. Interestingly, in order to maintain the desired mid-morning stomatal conductance in the $\mathrm{SD}$ vines $\left(0.05<g_{\mathrm{s}}<0.15 \mathrm{~mol} \mathrm{~m}^{-2} \mathrm{~s}^{-1}\right)$ progressively lower $\theta$ had to be applied (from $13 \%$ on day 14 to $9 \%$ on day 39) during the acclimation period, probably due to the vines' acclimation to low water availability. The transient water deficit treatment (TD) underwent three cycles of dehydration-rehydration in which $\theta$ fluctuated between 14 and 39\% during each cycle (Fig. 2).

In accordance with $\theta, g_{\mathrm{s}}$ throughout the acclimation period was higher in the WW vines $\left(0.217-0.563 \mathrm{~mol} \mathrm{~m}^{-2} \mathrm{~s}^{-1}\right)$, lower in the SD vines $\left(0.187-0.027 \mathrm{~mol} \mathrm{~m}^{-2} \mathrm{~s}^{-1}\right)$, and fluctuated between 0.034 and $0.341 \mathrm{~mol} \mathrm{~m}^{-2} \mathrm{~s}^{-1}$ in the TD vines (Fig. 2b; Table S2). On some days, the SD vines exceeded the $g_{\mathrm{s}}$ values planned for this treatment $\left(g_{\mathrm{s}}<0.15 \mathrm{~mol} \mathrm{~m}^{-2} \mathrm{~s}^{-1}\right)$, reflecting the difficulty to predict the stomatal response to a certain $\theta$ over time and under different atmospheric conditions. The measured $g_{\mathrm{s}}$ values suggest that the SD vines experienced moderate stress during most of the acclimation period $\left(g_{\mathrm{s}}\right.$ between 0.10 and $\left.0.05 \mathrm{~mol} \mathrm{~m}^{-2} \mathrm{~s}^{-1}\right)$, with severe stress between the 37th and the 39th day $\left(g_{\mathrm{s}}<0.05-\right.$ mol m${ }^{-2} \mathrm{~s}^{-1}$; according to the stress definitions of Medrano et al. 2002). The TD treatment reached minimum $g_{\mathrm{s}}$ values of 0.137, 0.089, and $0.034 \mathrm{~mol} \mathrm{~m}^{-2} \mathrm{~s}^{-1}$ on the 13th, 28th and 39th DOE, respectively. After the acclimation period (i.e. after the 39th day of the experiment), all treatments were irrigated as the WW and $g_{\mathrm{s}}$ increased to non-stressed levels, reaching values of $0.27-0.31 \mathrm{~mol} \mathrm{~m}^{-2} \mathrm{~s}^{-1}$ (Fig. 2b), which implies that no permanent damage was inflicted by the drought stress.

During the whole acclimation period lower ABA concentration was measured in the WW, higher in the SD and fluctuated in the TD following the $\theta$ trend. Interestingly, when TD vines were exposed to low $\theta$, they exhibited significantly higher ABA concentration than $\mathrm{SD}$, regardless of similar $\theta$. However, there was no trace of these high levels following 6 days of rehydration, suggesting that the effect of water stress (Tombesi et al. 2015) was eliminated (Fig. 2c; Table S3).

\section{Leaf physiological adjustments following acclimation}

The differences in irrigation amounts resulted in large differences between the treatments in both leaf area and vine mass (Table 1). After the acclimation, the WW vines had significantly higher $(P<0.05)$ total leaf area $(3147$ vs. $1206 \mathrm{~cm}^{2}$ vine $^{-1}$ ), fresh weight (117 vs. $36 \mathrm{~g} \mathrm{vine}^{-1}$ ), and dry weight ( 28 vs. $8 \mathrm{~g}_{\text {vine }}{ }^{-1}$ ) when compared to the SD treatment. The leaf area and the fresh and dry weights of the TD vines were intermediate between those of the WW and $\mathrm{SD}$ vines.

To assess the vines acclimation to low water availability we characterized the difference between the diameter of the 
xylem vessels, the xylem vulnerability to cavitation, and the modification of the cell characteristics as can be derived from the pressure-volume curve analysis. The exposure to low irrigation resulted in slightly different $(P>0.05)$ osmotic potential at full turgor $\left(\pi_{100}\right.$; $\mathrm{SD}=-1.1, \mathrm{TD}=-1.07$, and $\mathrm{WW}=-1.02 \mathrm{MPa})$, and cell modulus of elasticity $(\varepsilon ; \mathrm{WW}=6.1 ; \mathrm{TD}=8.2$, $\mathrm{SD}=7.2 \mathrm{MPa})$. The turgor loss point $\left(\Psi_{\mathrm{TLP}}\right)$ was significantly lower $(P<0.05)$ in the vines acclimated under SD coupled with a lower relative water content at turgor loss point $\left(\mathrm{RWC}_{\mathrm{TLP}}\right)(-1.31 \mathrm{MPa}$ and $88 \%$, respectively) when compared to those acclimated under TD $(-1.17 \mathrm{MPa}$ and $91 \%$, respectively) or WW ( $-1.08 \mathrm{MPa}$ and $92 \%$, respectively) throughout the experiment (Table 2).

Measurements of xylem architecture showed that the imposed acclimation treatments resulted in significant differences in xylem differentiation (Table 3; Fig. S2). The WW treatment bore the largest leaf area, petiole crosssection area, average xylem vessel diameter, total xylem area, and theoretical specific hydraulic conductivity $\left(k_{\mathrm{ts}}\right)$. While the SD vines had the smallest leaf area $(\mathrm{WW}=169$; $\mathrm{TD}=156 ; \mathrm{SD}=119 \mathrm{~cm}^{2}$ ), petiole cross-section area $\left(\mathrm{WW}=5.58 ; \quad \mathrm{TD}=5.47 ; \quad \mathrm{SD}=4.35 \mathrm{~mm}^{2}\right)$, and total xylem vessels area $\quad(\mathrm{WW}=0.16 ; \quad \mathrm{TD}=0.13$; $\mathrm{SD}=0.12 \mathrm{~mm}^{2}$ ), the TD were the smallest in average xylem vessel diameter $\quad(\mathrm{WW}=20.6 ; \quad \mathrm{TD}=18.3$; $\mathrm{SD}=20 \mu \mathrm{m}) \quad$ and $\quad k_{\mathrm{ts}} \quad(\mathrm{WW}=13.82 ; \quad \mathrm{TD}=8.06 ;$ $\left.\mathrm{SD}=13.72 \mathrm{mmol} \mathrm{m}^{-1} \mathrm{~s}^{-1} \mathrm{MPa}\right)$. Categorizing xylem vessels based on their size (Fig. 3a) further showed that TD vines had higher proportion of small diameter vessels $(10-20 \mu \mathrm{m})$ and a significantly lower proportion of high diameter vessels $(>25 \mu \mathrm{m})$ as compared with the other treatments. On average, less than 5 vessels per petiole were larger than $30 \mu \mathrm{m}$ in the TD vines, compared with 15 or 10 vessels per petiole in the WW and SD, respectively. Accordingly in the WW vines, much larger proportion of conductance relied on large vessels as compared with the TD (Fig. 3b).

The analysis of the xylem vulnerability curves (VC) (Fig. 4) resulted in substantial differences between the treatments, but not as expected. Comparison of the water potential at which half of the conductance is lost $\left(\mathrm{PLC}_{50} \%\right)$ showed that the WW treatment, though bearing the largest vessels (normally coinciding with higher xylem vulnerability), was the least vulnerable to cavitation $\left(\mathrm{PLC}_{50} \%=-1.31 \mathrm{MPa}\right)$. On the other hand, the SD treatment was significantly the most vulnerable to cavitation $\left(\mathrm{PLC}_{50} \%=-1.09 \mathrm{MPa}\right)$. The $\mathrm{VC}$ of the TD treatment was intermediate $\left(\mathrm{PLC}_{50} \%=-1.18 \mathrm{MPa}\right)$. A similar range of variance $(\sim 0.3 \mathrm{MPa})$ was also measured for the $12 \%$ loss of conductance $\left(\mathrm{PLC}_{12} \%\right.$; $\mathrm{WW}=-0.91 \mathrm{MPa} ; \quad \mathrm{TD}=0.7 \mathrm{MPa} ; \quad \mathrm{SD}=-0.6 \mathrm{MPa})$ and $88 \%$ loss of conductance $\left(\mathrm{PLC}_{88} \% ; \quad \mathrm{WW}=\right.$ $-1.83 \mathrm{MPa}$; TD $=-1.67 \mathrm{MPa} ; \mathrm{SD}=-1.52 \mathrm{MPa})$. The treatments had similar slopes $(\mathrm{WW}=108 \% / \mathrm{MPa}$; $\mathrm{TD}=103 \% / \mathrm{MPa} ; \mathrm{SD}=116 \% / \mathrm{MPa})$ but the linearized
Table 2 The leaf pressure-volume curve (PV) parameters of wellwatered (WW), transient water deficit (TD), and sustained water deficit (SD) vines after the acclimation period: osmotic potential at full turgor $\left(\pi_{100}\right)$, mean bulk modulus of elasticity $(\varepsilon)$, water potential at turgor loss point $\left(\Psi_{\mathrm{TLP}}\right)$, and relative water content at turgor loss point $\left(\mathrm{RWC}_{\mathrm{TLP}}\right)$

\begin{tabular}{lllll}
\hline Treatment & $\pi_{100}(\mathrm{MPa})$ & $\varepsilon(\mathrm{MPa})$ & $\Psi_{\text {TLP }}(\mathrm{MPa})$ & $\mathrm{RWC}_{\text {TLP }}(\%)$ \\
\hline WW & $-1.02 \pm 0.03^{\mathrm{a}}$ & $6.07 \pm 0.55^{\mathrm{a}}$ & $-1.08 \pm 0.03^{\mathrm{b}}$ & $92.06 \pm 0.90^{\mathrm{a}}$ \\
TD & $-1.07 \pm 0.04^{\mathrm{a}}$ & $8.16 \pm 0.78^{\mathrm{a}}$ & $-1.17 \pm 0.04^{\mathrm{ab}}$ & $90.91 \pm 1.24^{\mathrm{a}}$ \\
SD & $-1.10 \pm 0.05^{\mathrm{a}}$ & $7.17 \pm 0.71^{\mathrm{a}}$ & $-1.31 \pm 0.06^{\mathrm{a}}$ & $88.21 \pm 2.68^{\mathrm{a}}$
\end{tabular}

Values are mean \pm SE $(n=9)$. Different letters within a column indicate significant differences between treatments $(P<0.05)$ by Tukey Honest Significant Difference (HSD) test

Table 3 The petiole xylem architecture of well-watered (WW), transient deficit (TD), or sustained deficit (SD) vines after the acclimation period: the petiole cross-section area, single leaf area
(LA), number of bundles, number of xylem vessels, the average xylem vessel diameter $\left(D_{\text {vessel }}\right)$, the total vessel area $\left(\mathrm{VA}_{\text {total }}\right)$ and the theoretical leaf area specific conductance $\left(k_{\mathrm{ts}}\right)$

\begin{tabular}{llllllll}
\hline Treatment & Petiole area $\left(\mathrm{mm}^{2}\right)$ & $\mathrm{LA}^{*}\left(\mathrm{~cm}^{2}\right)$ & Bundles $(\#)$ & Vessels $(\#)$ & $D_{\text {vessel }}(\mu \mathrm{m})$ & $\mathrm{VA}_{\text {total }}\left(\mathrm{mm}^{2}\right)$ & $k_{\text {ts }}\left(\mathrm{mmol} \mathrm{m}^{-1} \mathrm{~s}^{-1} \mathrm{MPa}^{\mathrm{a}}\right)$ \\
\hline WW & $5.58 \pm 0.29^{\mathrm{a}}$ & $168.9 \pm 2.2^{\mathrm{a}}$ & $25.7 \pm 0.96^{\mathrm{a}}$ & $424.0 \pm 34.1^{\mathrm{ab}}$ & $20.6 \pm 0.65^{\mathrm{a}}$ & $0.160 \pm 0.010^{\mathrm{a}}$ & $13.82 \pm 0.01^{\mathrm{a}}$ \\
TD & $5.47 \pm 0.30^{\mathrm{ab}}$ & $155.9 \pm 2.5^{\mathrm{b}}$ & $26.0 \pm 1.16^{\mathrm{a}}$ & $468.3 \pm 38.0^{\mathrm{a}}$ & $18.3 \pm 0.41^{\mathrm{b}}$ & $0.135 \pm 0.012^{\mathrm{ab}}$ & $8.06 \pm 0.01^{\mathrm{b}}$ \\
SD & $4.33 \pm 0.37^{\mathrm{b}}$ & $119.4 \pm 3.6^{\mathrm{c}}$ & $22.6 \pm 1.29^{\mathrm{a}}$ & $336.3 \pm 21.4^{\mathrm{b}}$ & $20.0 \pm 0.28^{\mathrm{a}}$ & $0.120 \pm 0.003^{\mathrm{b}}$ & $13.72 \pm 0.00^{\mathrm{a}}$
\end{tabular}

Samples were collected only from leaves that developed after the imposition of the acclimation treatments. Values are mean \pm SE $(n=7)$. Different letters within a column indicate significant differences between treatments $(P<0.05)$ by Tukey Honest Significant Difference (HSD) test

* LA values presented in Table 1 account also for the small leaves in the plant and thus are significantly smaller than the values below. 


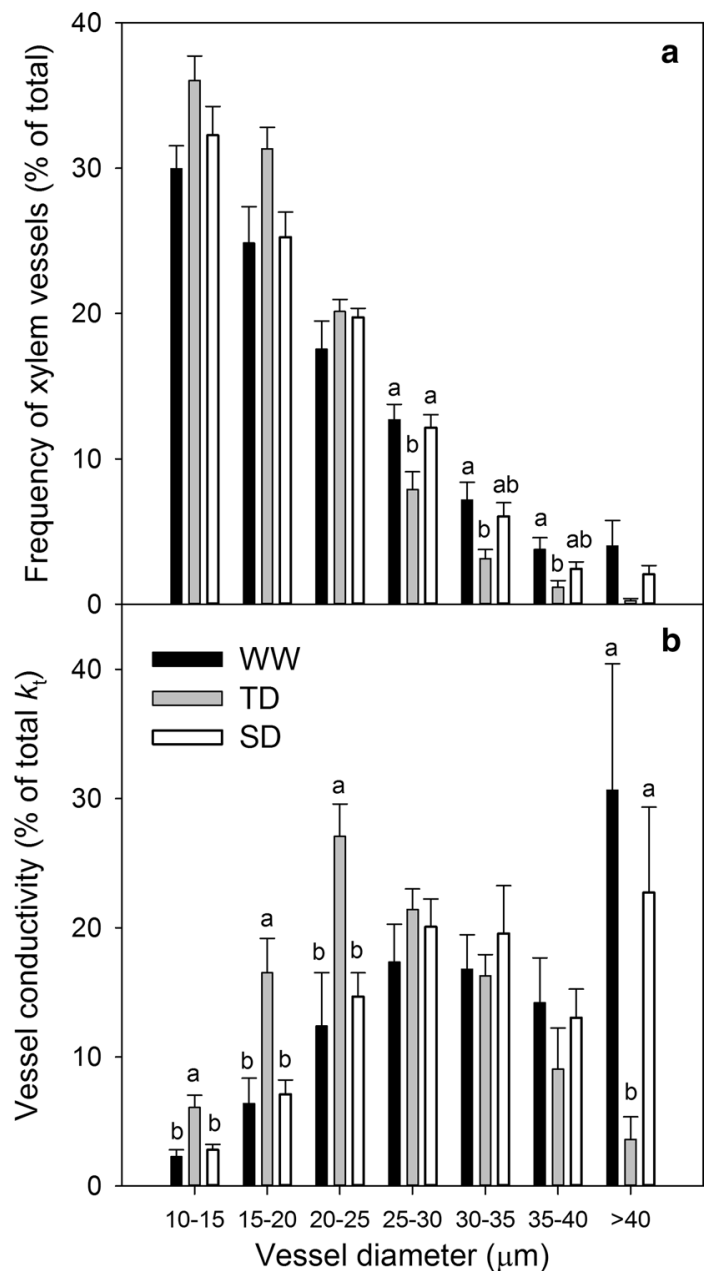

Fig. 3 The contribution of different vessel diameter class in petiole cross-section in $\mathbf{a}$ the relative frequency of vessels number and $\mathbf{b}$ the relative vessel theoretical conductivity $\left(k_{\mathrm{t}}\right)$ in well-watered (WW), transient deficit (TD), and sustained deficit (SD) acclimated vines. Data are mean $\pm \mathrm{SE}, n=7$

model of the $\mathrm{VC}$ revealed significant differences between the treatments $(P=0.0003)$ (Fig. S3).

\section{Hydraulic regulation of drought-acclimated grapevines}

In light of the above-mentioned differences in the physiological characteristics between the treatments, the hydraulic regulation of the acclimated vines was compared in response to different levels of drought. The vines' water relations were measured over the course of a day at three different levels of $\theta(43,17$ or $12 \%)$, presenting clear differences between the treatments. At high soil water availability $(\theta=43 \%$; Fig. $5 \mathrm{a}, \mathrm{d})$, vines from all treatments maintained similar $\Psi_{\mathrm{s}}(\sim-0.45 \mathrm{MPa})$ and $g_{\mathrm{s}}$ $\left(0.2-0.45 \mathrm{~mol} \mathrm{~m}^{-2} \mathrm{~s}^{-1}\right.$; Fig. 5a) throughout the day. As soon as the vines were subjected to low soil water content

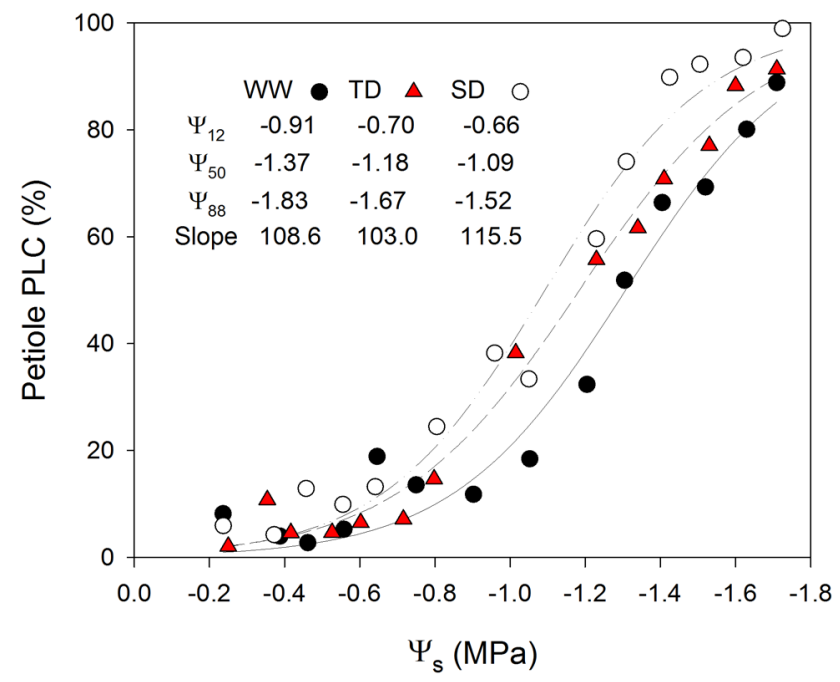

Fig. 4 The petiole xylem vulnerability curves (VC) of the wellwatered (WW), transient deficit (TD), and sustained deficit (SD) treatments. A sigmoidal regression (3 parameters) between the petiole percent loss of conductivity due to embolism (PLC) and the stem water potential $\left(\Psi_{\mathrm{s}}\right)$. Data are means of three petioles from the same shoot. All VC parameters-stem xylem tension causing 12, 50, or $88 \%$ loss of hydraulic conductivity $\left(\Psi_{12}, \Psi_{50}, \Psi_{88} ; \mathrm{MPa}\right)$, and the sigmoidal regression slope $(\% / \mathrm{MPa})$ were derived from the sigmoidal regression of the entire data set

$(\theta=12$ or $17 \%$; Fig. $5 b, c, e, f)$, the SD plants maintained higher $g_{\mathrm{s}}$ as compared with the TD and WW ones. For example, when $\theta$ was $17 \%$ (Fig. $5 \mathrm{~b}$, e), the $g_{\mathrm{s}}$ in SD vines at midday was significantly higher than in WW vines $(0.3$ and $0.1 \mathrm{~mol} \mathrm{~m}^{-2} \mathrm{~s}^{-1}$, respectively) despite similar $\Psi_{\mathrm{s}}$ of $-0.79 \mathrm{MPa}$. When $\theta$ was $12 \%$ (Fig. $5 \mathrm{c}, \mathrm{f}$ ), midday $g_{\mathrm{s}}$ of the SD treatment were at least twice as high as the WW treatment (ranging from 0.009 to 0.034 compared with 0 to $0.004 \mathrm{~mol} \mathrm{~m}^{-2} \mathrm{~s}^{-1}$ in SD and WW, respectively) in every measurement.

When comparing the regressions of $k_{\text {plant }}, k_{\text {leaf }}$ or $g_{\mathrm{s}}$ against $\Psi_{\mathrm{s}}$, the SD treatment presented higher values for all of these parameters as compared with the WW and TD treatments (Fig. 6; statistical comparison at Table S4) at $\Psi_{\text {s }}$ lower than $-0.5 \mathrm{MPa}$. As $\Psi_{\mathrm{s}}$ became more negative, $g_{\mathrm{s}}$, $k_{\text {leaf }}$ and $k_{\text {plant }}$ were reduced, regardless of the acclimation treatment. The $g_{\mathrm{s}}$ and $k_{\text {plant }}$ reduction was sharper in the WW and TD as compared with SD as $\Psi_{\mathrm{s}}$ became more negative, presenting the modification of the vines' water relations in respect to the irrigation treatment during the acclimation period. However, comparison of petiole embolism and $k_{\text {leaf }}$ reduction showed that the large majority of $k_{\text {leaf }}$ reduction in all treatments (from above 30 to below $10 \mathrm{mmol} \mathrm{m}{ }^{-2} \mathrm{~s}^{-1} \mathrm{MPa}^{-1}$ ) occurred at $\Psi_{\mathrm{s}}$ higher than $-0.6 \mathrm{MPa}$, equivalent only to less than $20 \%$ PLC (Fig. 7). The difference between $50 \% k_{\text {leaf }}$ reduction and $50 \%$ PLC was at least $0.4 \mathrm{MPa}$ (in SD) and up to $0.8 \mathrm{MPa}$ (in WW). Even more so, the SD vines were more vulnerable to 


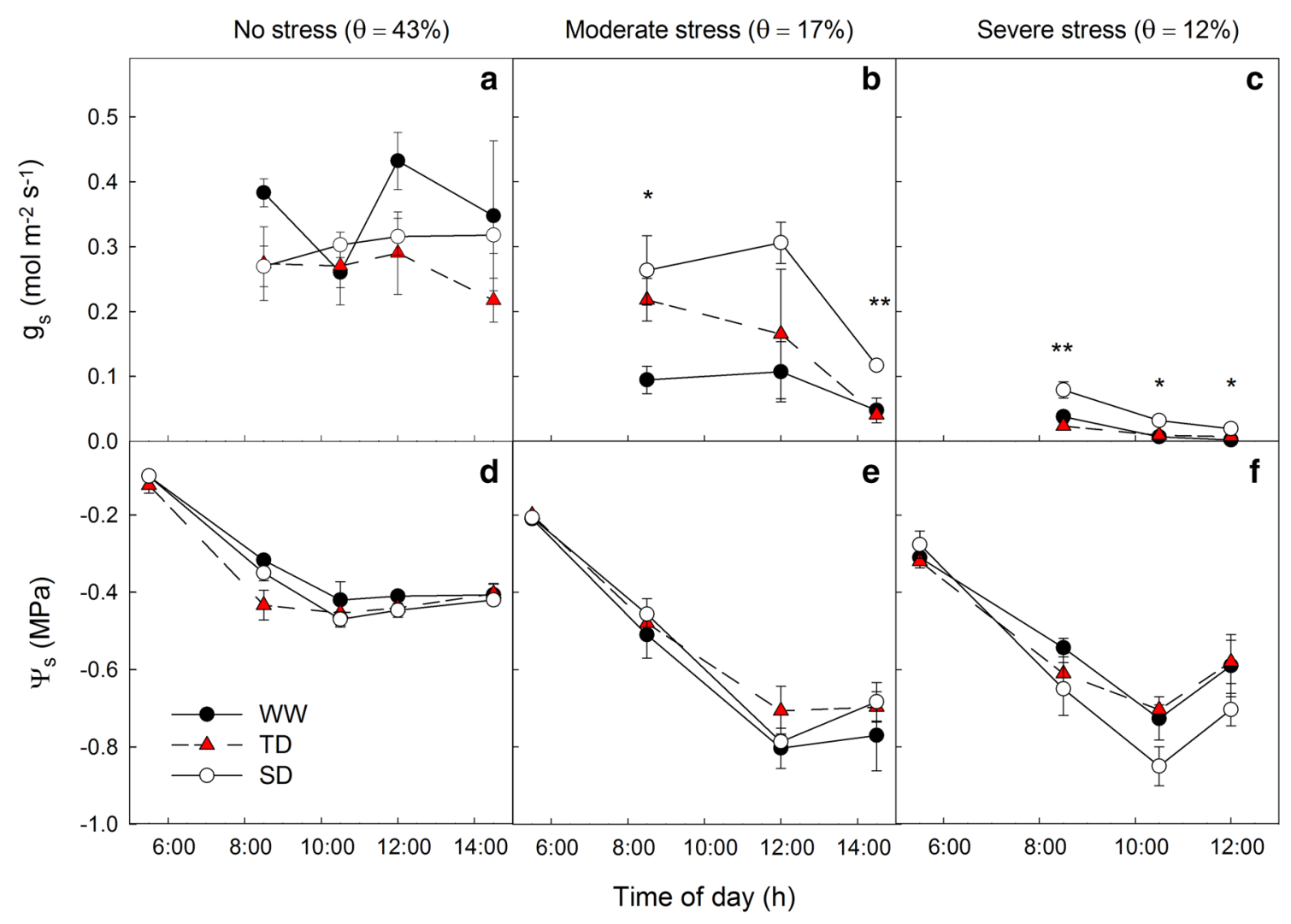

Fig. 5 Daily course of the stomatal conductance $\left(\mathbf{a}-\mathbf{c}, g_{\mathrm{s}}\right)$ and the stem water potential $\left(\mathbf{d}-\mathbf{f}, \Psi_{\mathrm{s}}\right)$ of vines acclimated under well-watered (WW), transient deficit (TD), and sustained deficit (SD) condition, when subjected to no-water stress $(\mathbf{a}, \mathbf{d})$, moderate water stress $(\mathbf{b}, \mathbf{e})$, and severe water stress $(\mathbf{c}, \mathbf{f})$ conditions. Following the acclimation

cavitation than the WW ones, but showed milder reduction in $k_{\text {leaf }}$ as $\Psi_{\mathrm{s}}$ became more negative. On the other hand, the $k_{\text {leaf }}$ decline of each treatment could be associated with their $\Psi_{\mathrm{TLP}}\left(\sim 0.2 \mathrm{MPa}\right.$ difference in $\Psi_{\mathrm{TLP}}$ and $k_{\text {leaf }} 50 \%$ between the WW and SD) and explain the sharper $k_{\text {leaf }}$ reduction of the WW treatment (Fig. 7).

\section{Discussion}

The results support the hypotheses that acclimation to water deficit modifies both the grapevine hydraulic properties and the regulation of gas exchange in future drought events; drought acclimation resulted in morphological modifications of the hydraulic system in grapevines, which in turn allowed the vines to maintain higher $g_{\mathrm{s}}$ and $k_{\text {plant }}$ (compared to vines acclimated to high water availability) under drought conditions. In agreement with previous research (Patakas et al. 1997; Martorell et al. 2014), the vines acclimated to low soil water content had a lower leaf area (LA) and $\Psi_{\mathrm{TLP}}$ than vines acclimated to well-watered conditions. These modifications induced by period all vines were maintained under full irrigation before subjected to different soil water content $(\theta)$. Data are mean $\pm \mathrm{SE}, n=3$. * or ** represents significant difference $(P<0.05$ or $P<0.01)$ between the WW and SD treatment

the acclimation possibly contributed, in the subsequent drought event, to the maintenance of higher rates of gas exchange while going to lower $\Psi_{s}$. Similar results were observed in rice (Gupta et al. 1989) and sunflowers (Matthews et al. 1984), where acclimation to water deficit resulted in osmotic adjustment, which in turn lead to higher $g_{\mathrm{s}}$ and growth in a subsequent drought event. The accumulation of solutes under water deficit conditions is well documented in grapevine (Patakas et al. 2002; Hochberg et al. 2013), and the consequential reduction of $\Psi_{\text {TLP }}$ (Table 2) can explain the maintenance of improved leaf turgor, leading to higher stomatal conductance (Franks and Farquhar 1998). The modification of $g_{\mathrm{s}} \sim \Psi_{\mathrm{s}}$ relation is particularly interesting when considering its high variability in grapevines, suggesting that in addition to the soil type and the scion-rootstock interaction (Lavoie-Lamoureux et al. 2017), also the acclimation conditions should be considered.

Growth inhibition, expressed by the large size differences between treatments (as leaf area or weight; Table 1), is one of the first and most noticeable responses to water limitation as it allows plants to conserve resources (Lebon 


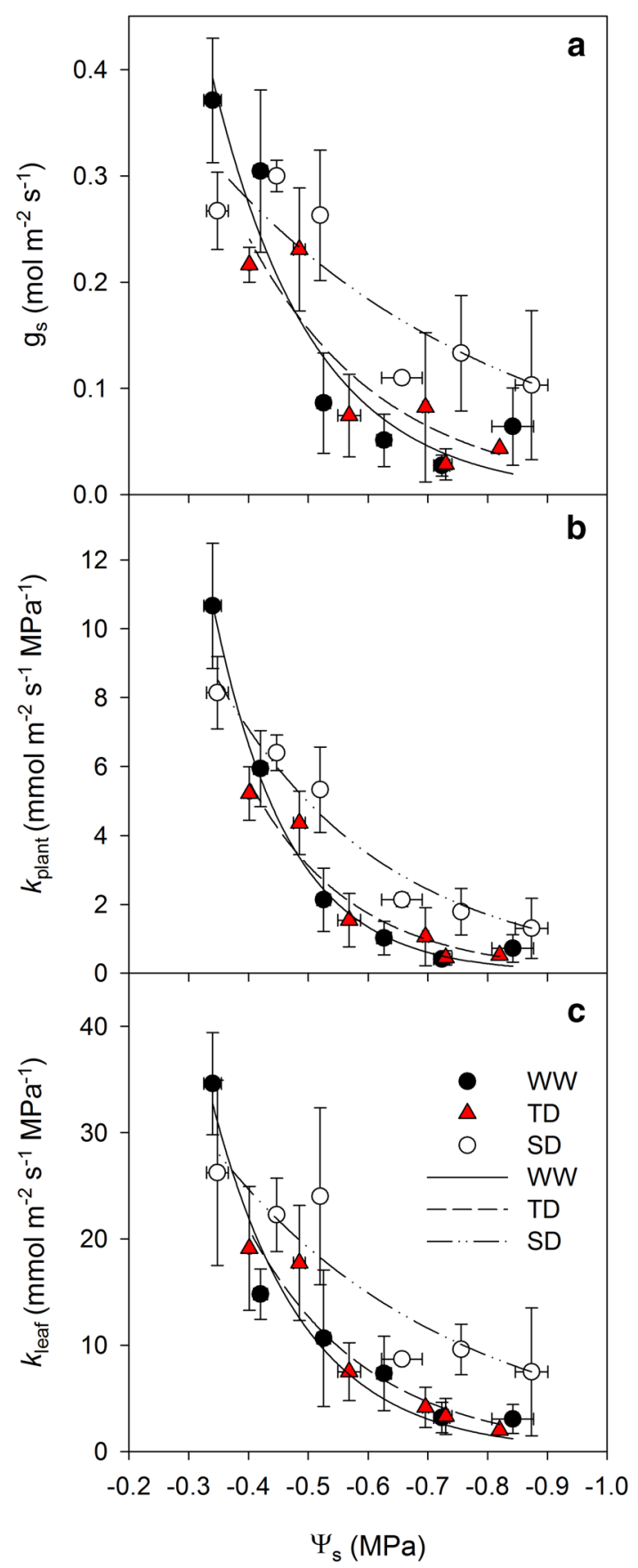

Fig. 6 Regression between stem water potential $\left(\Psi_{\mathrm{s}}\right)$ and stomatal conductance $\left(\mathbf{a}, g_{\mathrm{s}}\right)$, the whole plant conductance $\left(\mathbf{b}, k_{\text {plant }}\right.$ specific to leaf area), and the leaf conductance (c, $k_{\text {leaf }}$ specific to leaf area) of the well-watered (WW), transient deficit (TD), and sustained deficit (SD) treatments. Data were taken from the 3 days presented in Fig. 5 and averaged based on similar values of $\Psi_{\mathrm{s}}$. Each point is the mean $\pm \mathrm{SE}$, $n=3-7$

et al. 2006). Size differences could have created several hydraulics or non-hydraulic effect on gas exchange variability between treatments. Since transpiration is largely affected by the leaf area, but water supply was limited by the pot size (that was uniform across treatments), the

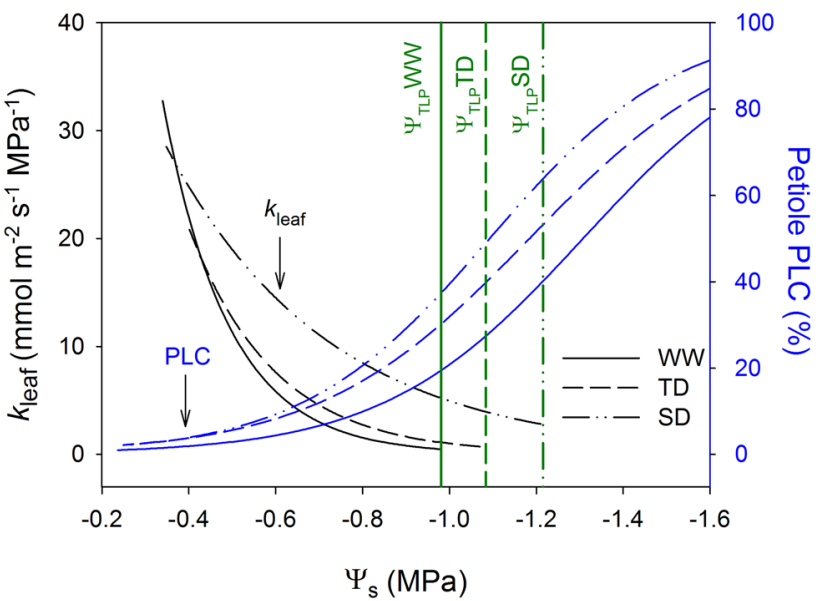

Fig. 7 Embolism in the petiole is not the primary cause for the reduction in leaf conductance. Regression between the stem water potential $\left(\Psi_{\mathrm{s}}\right)$ and leaf conductance ( $k_{\text {leaf }}$ specific to leaf area) or the percent loss of conductivity due to embolism in the petiole (PLC) of the well-watered (WW), transient water deficit (TD), and sustained water deficit (SD) acclimated vines. Sigmoidal regression of petiole PLC is reproduced from Fig. $4 . k_{\text {leaf }}$ regression is reproduced from Fig. 6c. The turgor loss point $\left(\Psi_{\mathrm{TLP}}\right)$ of $\mathrm{WW}$, TD, and SD was modified to $\Psi_{\mathrm{s}}$ (from $\Psi_{1}$ ) based on the average difference between $\Psi_{\mathrm{s}}$ and $\Psi_{1}(0.1 \mathrm{MPa}$ during the three full-day measurements $)$ and plotted as vertical lines

demand/supply ratio was significantly larger in the WW treatment, possibly leading to tighter down-regulation of $g_{\mathrm{s}}$ under stress conditions. To mitigate the differences in demand/supply ratio, we applied frequent irrigation (every $2 \mathrm{~h}$ ) that maintained a constant $\theta$ in the moderate and severe stress days (Fig. 5), thus diminishing the pot volume effect (Ray and Sinclair 1998). However, other authors suggested that it is the actual root length density (and not water availability), that affects stomatal closure (Shein and Pachepsky 1995). Moreover, other internal factor involving size such as sink demand, leaf sugar level, and starch storage were also shown to affect $g_{\mathrm{s}}$ (Goldschmidt and Huber 1992). These factors weren't the focus of this study, but should be further investigated to fully understand drought acclimation.

The comparison of the two acclimation treatments (TD and SD) showed that the difference in the acclimation processes is more than just a function of the drought integral (sum of water stress period). For example, when the TD treated vines were exposed to minimum $\theta, \mathrm{ABA}$ concentration was double the amount in TD than in $\mathrm{SD}$ vines. The difference in ABA concentration suggests that on a molecular level drought response was higher for the TD vines, an effect possibly correlated with the $\Psi_{\text {TLP }}$ differences between the treatments (McAdam and Brodribb 2016). On the same note, the average xylem vessel area and $k_{\mathrm{ts}}$ in the TD vines were significantly smaller than in SD vines. These differences could be attributed to the alteration of many regulatory and developmental processes that 
take effect shortly after drought is applied (Cramer et al. 2013). Accordingly, molecular regulation could continue shaping the development of well-watered plants in accordance with a previous water stress, possibly with epigenetics as the base for the stress "memory" (Chinnusamy and Zhu 2009). Under such conditions, the higher assimilation would also increase the resources that could be invested in the acclimation process, thus giving rise to the hypothesis that it would lead to larger modifications during the acclimation period. That said, many other acclimation processes, such as leaf area reduction and osmotic adjustment, underwent significantly larger modifications in the SD treatment than in TD, demonstrating the complexity of the acclimation process.

Remarkably, our results showed 4-8 bars difference between $50 \% k_{\text {leaf }}$ or $g_{\mathrm{s}}$ and $50 \%$ PLC (Fig. 7), challenging the commonly assumed involvement of embolism in the fast down-regulation of $g_{\mathrm{s}}$ (Zufferey et al. 2011) and $k_{\text {leaf }}$ (Sack and Holbrook 2006). In agreement, computed tomography of intact petioles showed very little embolism $(<25 \%)$ when $k_{\text {leaf }}$ (measured as in the current study) was completely down-regulated (Charrier et al. 2016). These findings reinforce the importance of other (than embolism) mechanisms in the down-regulation of $k_{\text {leaf }}$ : deformation of conduits under tension (Zhang et al. 2014, 2016), modification of the hydraulic properties of the extra-vascular compartment (Trifiló et al. 2016), or molecular regulation of membrane permeability through the interaction between aquaporins and ABA (Vitali et al. 2016), provide plausible explanations for the fast reduction in $k_{\text {leaf }}$ under water stress. ABA was recently shown to peak when approaching the $\Psi_{\text {TLP }}$ (McAdam and Brodribb 2016) and also to affect aquaporin-related genes expression and the $k_{\text {leaf }}$ (Vitali et al. 2016), thus explaining how the lower $\Psi_{\text {TLP }}$ of the SD vines led to higher $k_{\text {leaf }}$ under similar $\Psi_{\mathrm{s}}$ when compared to the WW treatment (illustrated in Fig. 6). Alternatively, leaf shrinkage, mediated through turgor pressure, has also been suggested to play a key role in the $k_{\text {leaf }}$ decline (Scoffoni et al. 2014). Although the mechanical nature of the interaction between turgor pressure and $k_{\text {leaf }}$ is not clear, it gains support from several other comparisons across grapevine cultivars, which showed that genotypes with lower $\Psi_{\mathrm{TLP}}$ tend to maintain higher $g_{\mathrm{s}}$ and $k_{\text {leaf }}$ (During and Loveys 1982; Tombesi et al. 2014; Martorell et al. 2014, 2015).

The larger vulnerability to cavitation in combination with the highest $g_{\mathrm{s}}$ and lowest $\Psi_{\mathrm{s}}$ observed in the SD vines, challenge previous suggestion of stomatal regulation through petiole cavitation (Zufferey et al. 2011). Rather, the combination implies that the majority of $g_{\mathrm{s}}$ down-regulation takes place before substantial limitation is caused by embolism in the petiole. Accordingly, our previous research demonstrated that the majority of $g_{\mathrm{s}}$ decline (to less than $20 \%$ of the optimal conditions) occurs at $\Psi_{\mathrm{s}}$ values higher than those leading to embolism in the leaf veins, petioles or shoots (Hochberg et al. 2016a, b). Similarly, in the current experiment $k_{\text {leaf }}$ and $g_{\mathrm{s}}$ were mutually down-regulated as $\Psi_{\mathrm{s}}$ became more negative, but in agreement with our previous publications, no petiole embolism was measured under such $\Psi_{\mathrm{s}}$ (Fig. 7). These results undermine the possibility that petiole cavitation controls stomatal regulation (Nardini and Salleo 2000) and strongly support the hypothesis that grapevines have evolved a strategy of cavitation avoidance, rather than one of cavitation tolerance with diurnal cycles of embolism repair (Hochberg et al. 2016b). It is important to mention that the correlation between xylem cavitation and stomatal regulation has been shown in several multi-species analyses (Cruiziat et al. 2002; Brodribb et al. 2003; Manzoni 2014). Our results do not contradict these finding, rather they suggest that the coordination between $g_{\mathrm{s}}$ and the petiole vulnerability to cavitation was shaped by evolution and is not a direct control mechanism.

Differently from our original hypothesis, vines that were acclimated to water deficit did not show improved resistance to cavitation (Fig. 4) although xylem architecture was modified. The literature suggests that smaller vessels, when compared to larger vessels in the xylem tissue of the same plant, normally exhibit improved vulnerability to cavitation (Tyree et al. 1994; Guet et al. 2015). It has also been found that exposure of hybrid poplars to drought resulted in both smaller vessel and improved cavitation resistance (Plavcova and Hacke 2012). In the current experiment, water deprivation led to smaller leaves with smaller xylem area, bearing smaller vessels (Table 3; Fig. 3a), as was previously reported for grapes (Lovisolo and Schubert 1998; Hochberg et al. 2015). The higher proportion of large vessels, which in turn contribute largely to the higher $k_{\mathrm{t}}$ in the WW treatment (Fig. 3b), should imply a lower resistance to cavitation. However, the vines acclimated to drought showed lower resistance to cavitation than the WW treatment, despite the acclimation effect on their morphological and anatomical traits.

These discrepancies could have arisen from two main causes: (1) the measured petioles were at different stages of development; and (2) the SD petioles suffered from cavitation fatigue. The first potential cause is reasonable, considering that during development the xylem has the potential to have significantly differing VC (Plavcova and Hacke 2012) and that the SD plants slowed development and growth (Table 1). The measured petioles were chosen before the treatments were applied, meaning that they had the same age (in days). However, reduced growth rate could have resulted in developmental changes (despite similar mature leaf appearance for all sampled leaves) that are known to impact xylem vulneravility to cavitation: alteration of the primary/secondary xylem ratio, lignin deposition, and/or pit pectin content (Herbette et al. 2015). 
Alternatively, cavitation fatigue (i.e. the phenomenon of increased cavitation vulnerability in response to cavitation/ refilling cycles; Hacke et al. 2001) could have increased the xylem vulnerability of the SD treatment. As the SD and TD vines were exposed to stress during the acclimation period, it is possible that some of their vessels were embolized and later refilled following rehydration. However, our VCs were constructed 3 weeks after rehydration, and the possibility of cavitation fatigue modifying VCs over times scales of this length is still in question. Stiller and Sperry (2002) suggested that the effect of cavitation fatigue is reduced as a function of the number of days since refilling, showing that in sunflowers it was completely reversible 4 days after irrigation. Conversely, other authors (Christensen-Dalsgaard and Tyree 2014; Schreiber et al. 2015) found that cavitation fatigue was still effective months after the cavitation event. Hacke et al. (2001) showed that the phenomenon is species dependent, implying that the discrepancy could be genetic. However, as neither the mechanism, nor the conditions, in which cavitation fatigue is inflicted or reversed are known, it is hard to determine if this was the cause for the larger vulnerability of the SD vines.

\section{Conclusion}

Our results show that grapevine acclimation to water deficit modifies the xylem architecture, $\Psi_{\mathrm{TLP}}$, and VCs. Some of the findings contradicted our original hypothesis and challenge several conceptions regarding plant hydraulics. For one, acclimation to water stress and differentiation of smaller vessel area in petioles did not lead to improved xylem resistance to cavitation. Additionally, petiole embolism cannot account for the reduction of $k_{\text {leaf }}$ and $g_{\mathrm{s}}$ under water stress. The interaction between $\Psi_{\mathrm{TLP}}$ and $k_{\text {leaf }}$, along with its effect on the plant's ability to maintain adequate gas exchange under stress should be further explored.

Author contribution statement $\mathrm{UH}$ and JCH conceived, designed and executed the research with the help of AGB. RDS performed microscopy analysis of petioles. AD and AF sampled and performed ABA analysis. HC assisted with hydraulic measurements. EP coordinated all the experiment activities. UH and JCH analyzed the data and wrote the manuscript. All authors discussed the results and revised the manuscript.

Acknowledgements Open access funding provided by University of Natural Resources and Life Sciences Vienna (BOKU). This research was part of the "IRRIGATE" project funded by the Italian Ministry of Foreign Affairs and the Israeli Ministry of Economy. The authors wish to thank Jessica Gersony for English editing. UH was supported by the Chateau Briand Fellowship.

\section{Compliance with ethical standards}

Conflict of interest The authors declare that they have no conflict of interest.

Open Access This article is distributed under the terms of the Creative Commons Attribution 4.0 International License (http://crea tivecommons.org/licenses/by/4.0/), which permits unrestricted use, distribution, and reproduction in any medium, provided you give appropriate credit to the original author(s) and the source, provide a link to the Creative Commons license, and indicate if changes were made.

\section{References}

Abràmoff MD, Magalhães PJ, Ram SJ (2004) Image processing with ImageJ. Biophotonics Int 11:36-42

Awad H, Barigah T, Badel E, Cochard H, Herbette S (2010) Poplar vulnerability to xylem cavitation acclimates to drier soil conditions. Physiol Plant 139:280-288

Bartlett MK, Zhang Y, Kreidler N, Sun S, Ardy R, Cao K, Sack L (2014) Global analysis of plasticity in turgor loss point, a key drought tolerance trait. Ecol Lett 17:1580-1590

Brodribb TJ, Holbrook N, Edwards E, Gutierrez M (2003) Relations between stomatal closure, leaf turgor and xylem vulnerability in eight tropical dry forest trees. Plant Cell Environ 26:443-450

Brodribb TJ, Feild TS, Jordan GJ (2007) Leaf maximum photosynthetic rate and venation are linked by hydraulics. Plant Physiol 144:1890-1898

Charrier G, Torres-Ruiz JM, Badel E, Burlett R, Choat B, Cochard H, Delmas CE, Domec JC, Jansen S, King A, Lenoir N, MartinStPaul N, Gambetta GA, Delzon S (2016) Evidence for hydraulic vulnerability segmentation and lack of xylem refilling under tension. Plant Physiol 172:1657-1668. doi:10.1104/pp.16.01079

Chinnusamy V, Zhu J (2009) Epigenetic regulation of stress responses in plants. Curr Opin Plant Biol 12:133-139

Christensen-Dalsgaard KK, Tyree MT (2014) Frost fatigue and spring recovery of xylem vessels in three diffuse-porous trees in situ. Plant Cell Environ 37:1074-1085

Cramer GR, Van Sluyter SC, Hopper DW, Pascovici D, Keighley T, Haynes PA (2013) Proteomic analysis indicates massive changes in metabolism prior to the inhibition of growth and photosynthesis of grapevine (Vitis vinifera L.) in response to water deficit. BMC Plant Biol 13:49

Cruiziat P, Cochard H, Améglio T (2002) Hydraulic architecture of trees: main concepts and results. Ann Forest Sci 59:723-752

Darwin F (1898) Observations on stomata. Proc R Soc Lond 63:413-417

During H, Loveys B (1982) Diurnal changes in water relations and abscisic acid in field grown Vitis vinifera cvs. I. Leaf water potential components and leaf conductance under humid temperate and semiarid conditions. Vitis 21:223-232

Fichot R, Barigah TS, Chamaillard S, Le Thiec D, Laurans F, Cochard H, Brignolas F (2010) Common trade-offs between xylem resistance to cavitation and other physiological traits do not hold among unrelated Populus deltoides $\times$ Populus nigra hybrids. Plant Cell Environ 33:1553-1568

Flexas J, Bota J, Escalona JM, Sampol B, Medrano H (2002) Effects of drought on photosynthesis in grapevines under field conditions: an evaluation of stomatal and mesophyll limitations. Funct Plant Biol 29:461-471

Franks P, Farquhar G (1998) A study of stomatal mechanics using the cell pressure probe. Plant Cell Environ 21:94-100 
Goldschmidt EE, Huber SC (1992) Regulation of photosynthesis by end-product accumulation in leaves of plants storing starch, sucrose, and hexose sugars. Plant Physiol 99:1443-1448

Guet J, Fichot R, Ledee C, Laurans F, Cochard H, Delzon S, Bastien C, Brignolas F (2015) Stem xylem resistance to cavitation is related to xylem structure but not to growth and water-use efficiency at the within-population level in Populus nigra L. J Exp Bot 66:4643-4652

Gupta AS, Berkowitz GA, Pier PA (1989) Maintenance of photosynthesis at low leaf water potential in wheat role of potassium status and irrigation history. Plant Physiol 89:1358-1365

Hacke UG, Stiller V, Sperry JS, Pittermann J, McCulloh KA (2001) Cavitation fatigue. Embolism and refilling cycles can weaken the cavitation resistance of xylem. Plant Physiol 125:779-786

Herbette S, Bouchet B, Brune N, Bonnin E, Cochard H, Guillon F (2015) Immunolabelling of intervessel pits for polysaccharides and lignin helps in understanding their hydraulic properties in Populus tremula $\times$ alba. Ann Bot 115:187-199

Hochberg U, Degu A, Toubiana D, Gendler T, Nikoloski Z, Rachmilevitch S, Fait A (2013) Metabolite profiling and network analysis reveal coordinated changes in grapevine water stress response. BMC Plant Biol 13:184

Hochberg U, Degu A, Gendler T, Fait A, Rachmilevitch S (2015) The variability in the xylem architecture of grapevine petiole and its contribution to hydraulic differences. Funct Plant Biol 42:357-365

Hochberg U, Albuquerque C, Rachmilevitch S, Cochard H, DavidSchwartz R, Brodersen CR, McElrone A, Windt CW (2016a) Grapevine petioles are more sensitive to drought induced embolism than stems: evidence from in vivo MRI and microCT observations of hydraulic vulnerability segmentation. Plant Cell Environ 39:1886-1894. doi:10.1111/pce.12688

Hochberg U, Herrera JC, Cochard H, Badel E (2016b) Short-time xylem relaxation results in reliable quantification of embolism in grapevine petioles and sheds new light on their hydraulic strategy. Tree Physiol 36:748-755. doi:10.1093/treephys/tpv145

Kolb KJ, Sperry JS (1999) Differences in drought adaptation between subspecies of sagebrush (Artemisia tridentata). Ecology 80:2373-2384

Lavoie-Lamoureux A, Sacco D, Risse PA, Lovisolo C (2017) Factors influencing stomatal conductance in response to water availability in grapevine: a meta-analysis. Physiol Plant. doi:10.1111/ppl. 12530

Lebon E, Pellegrino A, Louarn G, Lecoeur J (2006) Branch development controls leaf area dynamics in grapevine (Vitis vinifera) growing in drying soil. Ann Bot 98:175-185

Lovisolo C, Schubert A (1998) Effects of water stress on vessel size and xylem hydraulic conductivity in Vitis vinifera L. J Exp Bot 49:693-700. doi:10.1093/jxb/49.321.693

Lovisolo C, Perrone I, Carra A, Ferrandino A, Flexas J, Medrano H, Schubert A (2010) Drought-induced changes in development and function of grapevine (Vitis spp.) organs and in their hydraulic and non-hydraulic interactions at the whole-plant level: a physiological and molecular update. Funct Plant Biol 37:98-116

Manzoni S (2014) Integrating plant hydraulics and gas exchange along the drought-response trait spectrum. Tree Physiol 34:1031-1034

Martorell S, Medrano H, Tomàs M, Escalona JM, Flexas J, DiazEspejo A (2014) Plasticity of vulnerability to leaf hydraulic dysfunction during acclimation to drought in grapevines: an osmotic-mediated process. Physiol Plant 153:381-391

Martorell S, Diaz-Espejo A, Tomàs M, Pou A, El Aou-ouad H, Escalona JM, Vadell J, Ribas-Carbó M, Flexas J, Medrano H (2015) Differences in water-use-efficiency between two Vitis vinifera cultivars (Grenache and Tempranillo) explained by the combined response of stomata to hydraulic and chemical signals during water stress. Agric Water Manag 156:1-9
Matthews MA, Van Volkenburgh E, Boyer JS (1984) Acclimation of leaf growth to low water potentials in sunflower. Plant Cell Environ 7:199-206

McAdam SA, Brodribb TJ (2016) Linking turgor with ABA biosynthesis: implications for stomatal responses to vapour pressure deficit across land plants. Plant Physiol 171:2008-2016. doi: $10.1104 / \mathrm{pp} .16 .00380$

Medrano H, Eescalona JM, Bota J, Gulias J, Flexas J (2002) Regulation of photosynthesis of $\mathrm{C} 3$ plants in response to progressive drought: stomatal conductance as a reference parameter. Ann Bot 89:895-905

Nardini A, Salleo S (2000) Limitation of stomatal conductance by hydraulic traits: sensing or preventing xylem cavitation? Trees 15:14-24

Patakas A, Noitsakis B, Stavrakas D (1997) Adaptation of leaves of Vitis vinifera L. to seasonal drought as affected by leaf age. Vitis 36:11-14

Patakas A, Nikolaou N, Zioziou E, Radoglou K, Noitsakis B (2002) The role of organic solute and ion accumulation in osmotic adjustment in drought-stressed grapevines. Plant Sci 163:361-367

Plavcova L, Hacke UG (2012) Phenotypic and developmental plasticity of xylem in hybrid poplar saplings subjected to experimental drought, nitrogen fertilization, and shading. J Exp Bot 63:6481-6491

Rapaport T, Hochberg U, Rachmilevitch S, Karnieli A (2014) The effect of differential growth rates across plants on spectral predictions of physiological parameters. PLoS One 9:e88930

Ray JD, Sinclair TR (1998) The effect of pot size on growth and transpiration of maize and soybean during water deficit stress. J Exp Bot 49:1381-1386

Sack L, Holbrook NM (2006) Leaf hydraulics. Annu Rev Plant Biol 57:361-381

Scarth GW (1927) Stomatal movement: its regulation and regulatory role a review. Protoplasma 2:498-511

Schreiber SG, Hacke UG, Chamberland S, Lowe CW, Kamelchuk D, Bräutigam K, Campbell MM, Thomas BR (2015) Leaf size serves as a proxy for xylem vulnerability to cavitation in plantation trees. Plant Cell Environ 39:272-281

Scoffoni C, Vuong C, Diep S, Cochard H, Sack L (2014) Leaf shrinkage with dehydration: coordination with hydraulic vulnerability and drought tolerance. Plant Physiol 164:1772-1788

Shein EV, Pachepsky YA (1995) Influence of root density on the critical soil water potential. Plant Soil 171:351-357. doi:10. 1007/BF00010291

Sperry J, Hacke U, Oren R, Comstock J (2002) Water deficits and hydraulic limits to leaf water supply. Plant Cell Environ 25:251-263

Stiller V, Sperry JS (2002) Cavitation fatigue and its reversal in sunflower (Helianthus annuus L.). J Exp Bot 53:1155-1161

Tombesi S, Nardini A, Farinelli D, Palliotti A (2014) Relationships between stomatal behavior, xylem vulnerability to cavitation and leaf water relations in two cultivars of Vitis vinifera. Physiol Plant 152:453-464

Tombesi S, Nardini A, Frioni T, Soccolini M, Zadra C, Farinelli D, Poni S, Palliotti A (2015) Stomatal closure is induced by hydraulic signals and maintained by ABA in drought-stressed grapevine. Sci Rep 5:12449

Trifiló P, Raimondo F, Savi T, Lo Gullo MA, Nardini A (2016) The contribution of vascular and extra-vascular water pathways to drought-induced decline of leaf hydraulic conductance. J Exp Bot. doi:10.1093/jxb/erw268

Turner NC (1988) Measurement of plant water status by the pressure chamber technique. Irrig Sci 9:289-308

Tyree MT, Ewers FW (1991) The hydraulic architecture of trees and other woody plants. New Phytol 119:345-360 
Tyree MT, Davis SD, Cochard H (1994) Biophysical perspective of xylem evolution: is there a tradeoff of hydraulic efficiency for vulnerability to dysfunction? IAWA J 15:335-360

Van den Honert T (1948) Water transport in plants as a catenary process. Discuss Faraday Soc 3:146-153

Vitali M, Cochard H, Gambino G, Ponomarenko A, Perrone I, Lovisolo C (2016) VvPIP2; $4 \mathrm{~N}$ aquaporin involvement in controlling leaf hydraulic capacitance and resistance in grapevine. Physiol Plant 158:284-296. doi:10.1111/ppl.12463

Zhang YJ, Rockwell FE, Wheeler JK, Holbrook NM (2014) Reversible deformation of transfusion tracheids in Taxus baccata is associated with a reversible decrease in leaf hydraulic conductance. Plant Physiol 165:1557-1565

Zhang YJ, Rockwell FE, Graham AC, Alexander T, Holbrook NM (2016) Reversible leaf xylem collapse: a potential 'circuit breaker' against cavitation. Plant Physiol 172:2261-2274. doi:10.1104/pp.16.01191

Zufferey V, Cochard H, Ameglio T, Spring JL, Viret O (2011) Diurnal cycles of embolism formation and repair in petioles of grapevine (Vitis vinifera cv. Chasselas). J Exp Bot 62:3885-3894 